\title{
GERENCIAMENTO DE RESÍDUOS LABORATORIAIS: RECUPERAÇÃO DE ELEMENTOS E PREPARO PARA DESCARTE FINAL
}

\author{
Júlio Carlos Afonso*, Leandro Anido Noronha, Renata Pinheiro Felipe e Nicolas Freidinger \\ Departamento de Química Analítica, Instituto de Química, Universidade Federal do Rio de Janeiro, Centro de Tecnologia, \\ Bloco A, CP 68563, 21949-900 Rio de Janeiro - RJ
}

Recebido em 29/4/02; aceito em 9/10/02

\begin{abstract}
LABORATORY WASTE MANAGEMENT: RECOVERY OF ELEMENTS AND FINAL DISPOSAL. This work shows some laboratory waste management developed in order to recover some elements or to prepare the waste for a correct final disposal. The 25 elements chosen cover basically all chemical behaviors found for the metals in the Periodic Table. The treatments adopted were based on the classical behavior in aqueous solution (wet chemistry) but an important condition for a full success was the previous knowledge of the qualitative composition of the wastes treated. Some general trends were found: the final liquid waste was always saline and normally presented a higher volume than the original waste; most original wastes were acid in nature; steps such as solid-liquid separation, washing, evaporating and calcining were currently performed. This work was also a very good experience in chemistry in solution for students and showed them the need of treating wastes for a better environment.
\end{abstract}

Keywords: residue; metals recovery; waste treatment.

\section{INTRODUÇÃO}

O gerenciamento de resíduos químicos em laboratórios de ensino e pesquisa no Brasil começou a ser amplamente discutido nos anos de 1990, sendo de vital importância para as grandes instituições geradoras, incluindo as Universidades.

A ausência de um órgão fiscalizador, a falta de visão e o descarte inadequado levaram muitas Universidades a poluir o meio ambiente, promover o desperdício de material e arcar com o mau gerenciamento dos produtos sintetizados ou manipulados. Houve realmente um tempo onde os resíduos eram jogados na pia dos laboratórios sem preocupação sequer com a segurança do aluno. Dentro desse contexto, diversas Instituições Federais, Estaduais e Particulares no Brasil ${ }^{1-7}$ vêm buscando gerenciar e tratar seus resíduos de forma a diminuir o impacto causado ao meio ambiente, criando também um novo hábito a fazer parte da consciência profissional e do senso crítico dos alunos, funcionários e professores. Por exemplo, a Universidade Federal do Rio Grande do Sul (UFRGS) ${ }^{2}$ indicou que o impacto do programa de gerenciamento foi observado no comportamento de todos esses segmentos, que se mostraram entusiasmados por estarem contribuindo para a redução de danos ao meio ambiente.

A implementação ${ }^{5}$ de um programa de gestão de resíduos exige antes de tudo mudança de atitudes e, por isto, é uma atividade que traz resultados a médio e longo prazo, além de requerer a reeducação e uma persistência contínuas. Portanto, além da Instituição, disposta a implementar e sustentar o programa, o aspecto humano é muito importante, pois o êxito depende muito da colaboração de todos os membros da unidade geradora.

Este programa deve contemplar dois tipos de resíduos: o ativo (gerado continuamente nas atividades rotineiras na unidade geradora) e o passivo, que compreende todo aquele resíduo estocado, comumente não-caracterizado (frasco sem rótulo). A caracterização desse passivo nem sempre é possível, embora algumas vezes seja possível chegar a seu conteúdo através de testes de identificação ${ }^{8-9}$.

*e-mail: julio@iq.ufrj.br
Este passivo também tende a diminuir ou mesmo a acabar com a implementação do processo de rotulagem e identificação adequadas. Os resíduos gerados em atividades do laboratório de ensino podem ser facilmente caracterizados, inventariados e gerenciados, servindo mesmo para finalidades didáticas. Na UFRGS ${ }^{2}$ tem-se tratado resíduos de laboratório de graduação, onde o produto da recuperação vem sendo utilizado novamente nos experimentos. A partir dos laboratórios de ensino a gestão de resíduos pode envolver os laboratórios de pesquisa, onde os resíduos possuem uma maior diversidade quanto à natureza e à quantidade.

Alguns aspectos devem ser levados em consideração, os quais facilitam e ajudam no gerenciamento dos resíduos ${ }^{1,5,11}$ :

1) prevenir a geração dos mesmos, modificando ou substituindo o experimento por outro menos impactante;

2) minimizar a proporção de resíduos perigosos que são inevitavelmente gerados, através da utilização de pequenos volumes; o trabalho em microescala, além de gerar pouco resíduo, pode ainda diminuir os custos com reagentes a curto e longo prazo, embora algum investimento com vidraria de tamanho pequeno deva ser realizado $3,9,12$;

3) segregar e concentrar correntes de resíduos de modo a tornar viável e economicamente possível a atividade gerenciadora. A segregação dos resíduos facilita muito o trabalho, independentemente se o destino final é a incineração, o reuso ou a reciclagem ${ }^{2,3}$. Se existe uma separação dos resíduos por classes ou tipos, é possível tratá-los através de reações entre si ${ }^{8}$. Por exemplo, um resíduo contendo sulfeto pode ser usado para tratamento de um outro contendo metais pesados; assim não é consumido nenhum reagente para precipitar os metais e nenhum oxidante para tratar os sulfetos;

4) reciclar o componente material ou energético do resíduo. Embora exista um custo maior, pois é necessária a adição de reagentes ou o consumo energético, muitas vezes tal processo é bastante interessante. Um exemplo clássico é a reutilização de solventes orgânicos após tratamento e destilação dos mesmos;

5) tratar o resíduo da forma mais adequada possível, estocando pelo menor tempo possível;

6) dispor o resíduo de maneira segura. 
O Instituto de Química da Universidade Federal do Rio de Janeiro (IQ/UFRJ), consciente da necessidade de instruir o futuro profissional químico acerca dos problemas relativos ao meio ambiente, incluindo a questão da geração, tratamento e destino final dos resíduos químicos e outros assuntos correlatos, vem tomando diversas medidas nesse sentido. Em 1998, foi criada a disciplina "Tratamento de Resíduos Químicos de Laboratório", estruturada em visitas a indústrias químicas, palestras com especialistas na área, trabalhos inicial e final da disciplina e práticas de laboratório. No ano seguinte, foi criada a comissão de segurança, multidepartamental. Dentre outras atuações, destacam-se a elaboração de um manual de segurança e a remoção do passivo ambiental, correspondendo ao envio para incineração dos resíduos estocados nas dependências do Instituto, em alguns casos há mais de 30 anos. As Semanas de Química, organizadas pelos alunos do IQ/UFRJ, sempre dedicam um espaço para a realização de cursos de segurança em laboratório. Coletas seletivas de resíduos já são rotina nos laboratórios das disciplinas experimentais de todos os Departamentos. É cada vez mais notória no corpo discente a preocupação com o descarte indiscriminado de lixo ou de resíduos tóxicos de laboratórios ou de indústrias químicas. Todos já sabem que os resíduos químicos causam grandes problemas ambientais, levando à poluição de águas e solos por formas hidrossolúveis, contendo metais pesados tóxicos, bem como compostos cancerígenos, tais como sais de níquel(II), cromo(VI), compostos aromáticos, etc.

A partir de uma proposta de coleta diferenciada, a finalidade básica deste trabalho foi o desenvolvimento de rotinas de tratamento dos resíduos gerados em várias disciplinas experimentais de formação básica oferecidas pelo IQ/UFRJ, com vistas a atingir os seguintes objetivos: (a) recuperar (e reutilizar) elementos de interesse, com grau de pureza adequado; (b) obter rotas seguras de descarte de sólidos inservíveis (incinerar ou dispor em aterros para materiais perigosos [classe I]); c) obter efluentes líquidos neutralizados, isentos de metais pesados e espécies tóxicas que possam ser descartados na pia do laboratório. $\mathrm{O}$ material de trabalho corresponde a volumes gerados por 150 alunos em 4 disciplinas durante 2 anos e meio (5 períodos), envolvendo 25 elementos, que somam pouco mais de 32 litros, ( $220 \mathrm{~mL} / \mathrm{aluno})$. Alguns dos elementos selecionados correspondem a elementos de alto custo, ou de difícil aquisição, sendo alguns deles também bastante tóxicos. Mas há também outros argumentos que justificam o presente trabalho: ele permite ao aluno uma melhor conscientização acerca do problema que é a geração, o processamento e o descarte de resíduos químicos, tendo também a oportunidade de ampliar e consolidar a formação básica em química através da manipulação de elementos de comportamento químico bastante diferenciados entre si. Isto contribui para o fortalecimento de um "sentimento químico", que o profissional de hoje está perdendo e que, no entanto, é essencial para uma sólida formação deste mesmo profissional. O tratamento de cada resíduo possui uma particularidade e um nível de dificuldade que varia de acordo com a sua complexidade e a sua composição ${ }^{13}$.

\section{PARTE EXPERIMENTAL}

\section{Descrição sumária das amostras}

Foram tratados os resíduos das disciplinas Análise Qualitativa Inorgânica, Análise Qualitativa Inorgânica II, Química Analítica I e Introdução à Química Analítica, contendo os elementos listados na Tabela 1. Esses elementos são representativos do universo de trabalho em análise inorgânica feito pelos alunos de graduação no IQ/ UFRJ, inclusive em diversas linhas de pesquisa. Dado que a origem dos resíduos considerados pode ser plenamente conhecida a partir das práticas experimentais das disciplinas, pode-se listar, a nível qualitativo, a presença de cátions, ânions e outros compostos presentes no resíduo contendo um determinado elemento de interesse, conforme listado na Tabela 2. Esse tipo de abordagem, vital em matéria de tratamento, serve para justificar alguns resultados experimentais como o caráter redox (que nem sempre corresponde ao do elemento de interesse), o pH, a cor e o odor do resíduo.

\section{Tratamento de resíduos contendo prata}

Dado o elevado volume de resíduo processado $(3300 \mathrm{~mL})$ adicionou-se $\mathrm{NaOH}$ até $\mathrm{pH}$ 8-9, precipitando a prata solúvel existente. A solução, incolor, foi neutralizada com $\mathrm{HCl}$. No resíduo sólido adicionou-se, paulatinamente, $\mathrm{HNO}_{3}$ concentrado, sob aquecimento $\left(100{ }^{\circ} \mathrm{C}\right)$. Concentrou-se a solução até aproximadamente $50 \mathrm{~mL}$. Permaneceu um resíduo branco fosco, que mostrou ser solúvel em $\mathrm{NH}_{4} \mathrm{OH}$ (tratava-se do $\mathrm{AgCl}$ ). Assim, trabalhou-se com dois tipos de solução contendo prata: meio ácido e amoniacal. Adicionou-se, vagarosamente, $\mathrm{Na}_{2} \mathrm{~S}_{2} \mathrm{O}_{5}$ sólido à solução amoniacal até completa redução $\left(60{ }^{\circ} \mathrm{C}\right)$. Filtrou-se e lavou-se o precipitado com água destilada à temperatura ambiente (até filtrado com $\mathrm{pH}$ neutro). Na solução ácida, adicionou-se água e concentrou-se para remover o excesso de $\mathrm{NO}_{2}$. Adicionou-se vagarosamente $\mathrm{Na}_{2} \mathrm{~S}_{2} \mathrm{O}_{5}$ sólido até completa redução $\left(60^{\circ} \mathrm{C}\right)$ e centrifugou-se em seguida. A redução da prata se dá segundo ${ }^{14-17}$ :

$$
\begin{aligned}
& 3 \mathrm{H}_{2} \mathrm{O}+4 \mathrm{Ag}^{+}+\mathrm{Na}_{2} \mathrm{~S}_{2} \mathrm{O}_{5} \longrightarrow \mathrm{Na}_{2} \mathrm{SO}_{4}+4 \underline{\mathrm{Ag}}+\mathrm{H}_{2} \mathrm{SO}_{4}+4 \mathrm{H}^{+} \\
& \left(\mathrm{E}^{\mathrm{o}}=+1,34 \mathrm{~V}\right)
\end{aligned}
$$

Os dois precipitados foram lavados com água destilada a $60{ }^{\circ} \mathrm{C}$. Os resíduos finais em meio amoniacal e em meio ácido foram reunidos (teste para $\mathrm{Ag}$ negativo ${ }^{14-17}$ ) e neutralizados com $\mathrm{HCl}$ formandose um precipitado branco (contendo zinco).

\section{Processamento de resíduos contendo ouro}

Tratou-se o resíduo com água-régia sob aquecimento $\left(100{ }^{\circ} \mathrm{C}\right)$ e agitação (200 rpm). Ao final, permaneceu um sólido amarelo (enxofre), que foi isolado da solução. Concentrou-se esta última até cerca de $15 \mathrm{~mL}$, sem a formação de precipitado. Separou-se a solução em duas alíquotas iguais, para tentar a redução de ouro por adição de zinco metálico (meio levemente ácido) ou por adição de $\mathrm{H}_{2} \mathrm{O}_{2} \mathrm{em}$ meio básico.

Método A: ajustou-se o pH em 2-3 (NaOH), adicionou-se $\mathrm{Zn}^{\circ}$ em pó, sob aquecimento $\left(100{ }^{\circ} \mathrm{C}\right)$ e agitação $(200 \mathrm{rpm})$ até cessar a precipitação do ouro e até a dissolução total do excesso de zinco. Centrifugou-se o precipitado marrom, após coagulação deste $\left(100{ }^{\circ} \mathrm{C}\right)$, sendo lavado com água a $100{ }^{\circ} \mathrm{C}$ e recentrifugado. $\mathrm{O}$ ouro foi solubilizado em água régia e a solução foi levada à secura, formando $\mathrm{AuCl}_{3}$, um sólido amarelo. O resíduo, neutralizado com $\mathrm{NaOH}$, originou um precipitado pardo (Fe, $\mathrm{Sn}, \mathrm{Mn}, \mathrm{Zn}$ ) e um filtrado incolor.

Método B: Alcalinizou-se a solução até $\mathrm{pH}$ 8-9 com $\mathrm{NaOH}$, precipitando o Fe, Sn e Mn presentes, que foram isolados e o sólido foi lavado com $\mathrm{NaOH} 0,01 \mathrm{M}$ até teste negativo para ouro ${ }^{15-17}$. Realizou-se a redução do ouro com adição de $\mathrm{H}_{2} \mathrm{O}_{2} 36 \%$, a $50{ }^{\circ} \mathrm{C}$, até cessar a precipitação do ouro metálico impuro, como um fino sólido marrom. Após coagulação e centrifugação, lavou-se o sólido com $\mathrm{HCl}$, para eliminar qualquer hidróxido de outro metal co-precipitado com o ouro metálico, e em seguida com água $\left(100{ }^{\circ} \mathrm{C}\right)$. O ajuste do $\mathrm{pH}$ em 7 resultou num líquido final incolor, sem precipitado. $\mathrm{O}$ sólido marrom purificado foi solubilizado no mínimo de água-régia e a solução concentrada até secura, formando $\mathrm{AuCl}_{3}$. 
Tabela 1 - Dados de caracterização visual e físico-química dos resíduos iniciais

\begin{tabular}{|c|c|c|c|c|}
\hline $\begin{array}{l}\text { Elemento de } \\
\text { interesse }\end{array}$ & Descrição & $\begin{array}{c}\mathrm{pH} \\
\text { (papel universal) }\end{array}$ & $\begin{array}{l}\text { Volume tratado } \\
\qquad(\mathrm{mL})\end{array}$ & $\begin{array}{l}\text { Caráter redox (KI ou } \\
\mathrm{KMnO}_{4}+\mathrm{H}_{2} \mathrm{SO}_{4} \text { diluído) }\end{array}$ \\
\hline $\operatorname{Ag}\left(\mathrm{Ag}^{+}\right)$ & $\begin{array}{l}\text { Solução incolor contendo } \\
\text { sólido marrom }\end{array}$ & 2 & 3300 & Redutor \\
\hline $\mathrm{Au}\left(\mathrm{Au}^{3+}\right)$ & $\begin{array}{l}\text { Solução amarela contendo } \\
\text { sólidos pardo e branco }\end{array}$ & 1 & 140 & Redutor \\
\hline $\mathbf{B a}\left(\mathbf{B a}^{2+}\right)$ & $\begin{array}{l}\text { Solução alaranjada contendo } \\
\text { precipitado branco }\end{array}$ & 2 & 3000 & Oxidante \\
\hline $\mathrm{Be}\left(\mathrm{Be}^{2+}\right)$ & $\begin{array}{l}\text { Solução amarelada contendo } \\
\text { sólido pardo claro }\end{array}$ & 11 & 200 & Redutor \\
\hline $\mathbf{C d}\left(\mathbf{C d}^{2+}\right)$ & $\begin{array}{l}\text { Solução marrom contendo } \\
\text { sólido bege }\end{array}$ & 1 & 1500 & Redutor \\
\hline $\mathrm{Cr}\left(\mathrm{Cr}^{3+}+\mathrm{Cr}^{6+}\right)$ & Solução castanho-alaranjada & 0 & 10500 & Oxidante \\
\hline $\mathrm{Cu}\left(\mathrm{Cu}^{2+}\right)$ & $\begin{array}{l}\text { Solução azul contendo } \\
\text { precipitado branco }\end{array}$ & 2 & 2500 & Oxidante \\
\hline $\mathbf{E u}\left(\mathbf{E u}^{3+}\right)$ & $\begin{array}{l}\text { Solução incolor contendo } \\
\text { sólido branco }\end{array}$ & 4 & 33 & Redutor \\
\hline In $\left(\mathbf{I n}^{3+}\right)$ & $\begin{array}{l}\text { Solução incolor contendo } \\
\text { sólido preto }\end{array}$ & 14 & 70 & Redutor \\
\hline $\operatorname{Ir}\left(\operatorname{Ir}^{3+}+\mathbf{I r}^{4+}\right)$ & $\begin{array}{l}\text { Solução turva contendo } \\
\text { sólido branco }\end{array}$ & 2 & 30 & Redutor \\
\hline $\operatorname{Mn}\left(\mathrm{Mn}^{2+}+\mathrm{Mn}^{4+}\right)$ & $\begin{array}{l}\text { Solução incolor contendo } \\
\text { sólido pardo }\end{array}$ & 2 & 1500 & Redutor \\
\hline $\mathbf{N d}\left(\mathbf{N d}^{3+}\right)$ & $\begin{array}{l}\text { Solução incolor contendo } \\
\text { sólido róseo }\end{array}$ & 5 & 33 & Redutor \\
\hline $\mathrm{Ni}\left(\mathrm{Ni}^{2+}\right)$ & Solução verde & 3 & 2500 & Redutor \\
\hline Os $\left(O s^{4+}+O s^{8+}\right)$ & $\begin{array}{l}\text { Solução marrom contendo } \\
\text { sólido marrom }\end{array}$ & 1 & 50 & Redutor \\
\hline $\mathbf{P b}\left(\mathbf{P b}^{2+}\right)$ & Solução avermelhada & 2 & 2800 & Indiferente \\
\hline $\operatorname{Pr}\left(\operatorname{Pr}^{3+}\right)$ & $\begin{array}{l}\text { Solução incolor contendo } \\
\text { sólidos verde e branco }\end{array}$ & 1 & 15 & Redutor \\
\hline $\mathbf{P t}\left(\mathbf{P t}^{4+}\right)$ & $\begin{array}{l}\text { Solução amarelada contendo } \\
\text { sólido marrom }\end{array}$ & $0-1$ & 100 & Oxidante \\
\hline $\mathbf{R b}\left(\mathbf{R} \mathbf{b}^{+}\right)$ & $\begin{array}{l}\text { Solução amarela contendo } \\
\text { sólido pardo }\end{array}$ & 4 & 40 & Indiferente \\
\hline $\mathbf{R h}\left(\mathbf{R h}^{3+}\right)$ & $\begin{array}{l}\text { Solução incolor contendo } \\
\text { sólidos marrom escuro }\end{array}$ & 6 & 80 & Oxidante \\
\hline $\mathbf{R u}\left(\mathbf{R u}^{3+}\right)$ & $\begin{array}{l}\text { Solução marrom claro contendo } \\
\text { sólido marrom escuro }\end{array}$ & $1-2$ & 25 & Redutor \\
\hline $\mathrm{Se}\left(\mathrm{Se}^{\mathrm{o}}+\mathrm{Se}^{4+}\right)$ & $\begin{array}{l}\text { Solução turva marrom contendo } \\
\text { sólido preto }\end{array}$ & 1 & 300 & Redutor \\
\hline $\mathbf{S m}\left(\mathbf{S m}^{3+}\right)$ & $\begin{array}{l}\text { Solução incolor contendo } \\
\text { sólido amarelado }\end{array}$ & 1,5 & 40 & Duplo caráter \\
\hline $\mathrm{Sr}\left(\mathrm{Sr}^{2+}\right)$ & $\begin{array}{l}\text { Solução alaranjada contendo } \\
\text { precipitado branco }\end{array}$ & 2 & 3000 & Oxidante \\
\hline $\mathrm{Te}\left(\mathrm{Te}^{4+}\right)$ & $\begin{array}{l}\text { Solução amarela contendo } \\
\text { sólidos amarelo e branco }\end{array}$ & 8 & 170 & Duplo caráter \\
\hline $\mathrm{Tl}\left(\mathrm{Tl}^{+}\right)$ & Solução e sólido esverdeados & 12 & 100 & Redutor \\
\hline
\end{tabular}


Tabela 2 - Lista de analitos presentes nos resíduos dos elementos de interesse

\begin{tabular}{|c|c|c|c|}
\hline Elemento(s) & Outros cátions & Ânions & Outros compostos \\
\hline $\operatorname{Ag}\left(\mathbf{A g}^{+}\right)$ & $\mathrm{K}^{+}, \mathrm{H}^{+}, \mathrm{Zn}^{2+}, \mathrm{NH}_{4}^{+}$ & $\mathrm{Cl}^{-}, \mathrm{SO}_{4}^{2-}, \mathrm{I}^{-}, \mathrm{S}^{2-}, \mathrm{NO}_{3}^{-}$ & Nenhum \\
\hline $\mathrm{Au}\left(\mathrm{Au}^{3+}\right)$ & $\begin{array}{l}\mathrm{Na}^{+}, \mathrm{H}^{+}, \mathrm{Mn}^{2+}, \mathrm{K}^{+}, \\
\mathrm{NH}_{4}^{+}, \mathrm{Sn}^{2+}, \mathrm{Fe}^{3+}\end{array}$ & $\mathrm{F}^{-}, \mathrm{I}^{-}, \mathrm{Cl}^{-}, \mathrm{SO}_{4}^{2-}, \mathrm{S}^{2-}, \mathrm{C}_{2} \mathrm{O}_{4}^{2-}$ & $\begin{array}{l}\mathrm{H}_{2} \mathrm{O}_{2} \text {, tolueno, } \\
\text { rodamina-B }\end{array}$ \\
\hline $\mathrm{Ba}\left(\mathrm{Ba}^{2+}\right) \mathrm{Sr}\left(\mathrm{Sr}^{2+}\right)$ & $\mathrm{NH}_{4}^{+}, \mathrm{Mn}^{2+}, \mathrm{Na}^{+}, \mathrm{K}^{+}, \mathrm{Cl}^{-}$ & $\mathrm{CO}_{3}^{2-}, \mathrm{Cl}^{-}$, acetato, $\mathrm{CrO}_{4}^{2-}, \mathrm{I}^{-}$ & Ácido rodizônico \\
\hline $\mathrm{Be}\left(\mathrm{Be}^{2+}\right)$ & $\mathrm{Na}^{+}, \mathrm{Mn}^{2+}, \mathrm{K}^{+}, \mathrm{NH}_{4}^{+}, \mathrm{Fe}^{3+}$ & $\begin{array}{c}\mathrm{F}^{-}, \mathrm{I}^{-}, \mathrm{Cl}^{-}, \mathrm{SO}_{4}^{2-}, \mathrm{OH}^{-}, \mathrm{CO}_{3}^{2-}, \\
\mathrm{HCO}_{3}^{-}, \text {tartarato }\end{array}$ & Magneson I \\
\hline $\mathbf{C d}\left(\mathbf{C d}^{2+}\right)$ & $\mathrm{NH}_{4}^{+}, \mathrm{Mn}^{2+}, \mathrm{Na}^{+}, \mathrm{Cl}^{-}$ & $\mathrm{CO}_{3}^{2-}, \mathrm{S}^{2-}, \mathrm{I}^{-}$ & Ditizona \\
\hline 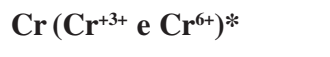 & $\mathrm{Na}^{+}, \mathrm{H}^{+}, \mathrm{K}^{+}$ & $\mathrm{SO}_{4}^{2-}$ & Nenhum \\
\hline $\mathrm{Cu}\left(\mathrm{Cu}^{2+}\right)$ & $\mathrm{NH}_{4}^{+}, \mathrm{Mn}^{2+}, \mathrm{Na}^{+}, \mathrm{Cl}^{-}$ & $\mathrm{S}^{2-},\left[\mathrm{Fe}(\mathrm{CN})_{6}\right]^{4-}, \mathrm{SO}_{4}^{2-}, \mathrm{I}^{-}$ & Nenhum \\
\hline $\begin{array}{l}\mathrm{Eu}, \mathbf{N d}, \mathrm{Pr} \text { e Sm } \\
\left(\mathrm{Eu}^{3+}, \mathrm{Nd}^{3+}, \mathrm{Pr}^{3+}, \mathrm{Sm}^{3+}\right)\end{array}$ & $\mathrm{Na}^{+}, \mathrm{H}^{+}, \mathrm{Mn}^{2+}, \mathrm{K}^{+}, \mathrm{NH}_{4}^{+}, \mathrm{Fe}^{3+}$ & $\begin{array}{c}\mathrm{PO}_{4}^{3--}, \mathrm{F}^{-}, \mathrm{NO}_{3}^{-}, \mathrm{I}^{-}, \mathrm{Cl}^{-}, \mathrm{SO}_{4}^{2-}, \\
\mathrm{NO}_{2}^{-}, \mathrm{Br}^{-}, \mathrm{C}_{2} \mathrm{O}_{4}^{2-}\end{array}$ & Nenhum \\
\hline In $\left(\operatorname{In}^{3+}\right)$ & $\mathrm{Na}^{+}, \mathrm{Mn}^{2+}, \mathrm{K}^{+}, \mathrm{NH}_{4}^{+}, \mathrm{Fe}^{3+}, \mathrm{Al}^{3+}$ & $\mathrm{F}^{-}, \mathrm{I}^{-}, \mathrm{Cl}^{-}, \mathrm{SO}_{4}^{2-}, \mathrm{OH}^{-}, \mathrm{S}^{2-}$ & $\begin{array}{l}\text { Aluminon, Alizarina-S, } \\
\text { tioacetamida }\end{array}$ \\
\hline $\operatorname{Ir}\left(\mathbf{I r}^{3+}+\mathbf{I r}^{4+}\right)$ & $\mathrm{K}^{+}, \mathrm{Zn}^{2+}, \mathrm{Mg}^{2+}, \mathrm{Mn}^{2+}, \mathrm{NH}_{4}^{+}$ & $\mathrm{Cl}^{-}, \mathrm{SO}_{4}^{2-}, \mathrm{S}^{2-}$ & Nenhum \\
\hline $\operatorname{Mn}\left(M^{2+}+M^{4+}\right)$ & $\mathrm{Zn}^{2+}, \mathrm{Bi}^{3+}, \mathrm{H}^{+}, \mathrm{NH}_{4}^{+}, \mathrm{Na}^{+}, \mathrm{Cl}^{-}$ & $\mathrm{CO}_{3}^{2-}, \mathrm{S}^{2-}, \mathrm{NO}_{3}^{-}, \mathrm{I}^{-}$ & Nenhum \\
\hline $\mathrm{Ni}\left(\mathrm{Ni}^{2+}\right)$ & $\mathrm{NH}_{4}^{+}, \mathrm{Mn}^{2+}, \mathrm{Na}^{+}, \mathrm{Cl}^{-}, \mathrm{Zn}^{2+}$ & $\mathrm{CO}_{3}^{2-}, \mathrm{S}^{2-}, \mathrm{I}^{-}, \mathrm{NO}_{3}^{-}$ & Dimetil-glioxima, etanol \\
\hline $\begin{array}{l}\text { Os }\left(\mathbf{O s}^{4+}+\mathbf{O s}^{8+}\right) \\
\operatorname{Ru}\left(\mathbf{R u}^{3+}\right)\end{array}$ & $\mathrm{K}^{+}, \mathrm{H}^{+}, \mathrm{Zn}^{2+}, \mathrm{NH}_{4}^{+}$ & $\mathrm{Cl}^{-}, \mathrm{SO}_{4}^{2-}, \mathrm{I}^{-}, \mathrm{S}^{2-}$ & ácido rubeâmico \\
\hline $\mathbf{P b}\left(\mathbf{P b}^{2+}\right)$ & $\mathrm{Cr}^{3+}, \mathrm{Zn}^{2+}, \mathrm{NH}_{4}^{+}, \mathrm{Mn}^{2+}, \mathrm{Na}^{+}, \mathrm{Cl}^{-}, \mathrm{H}^{+}$ & $\mathrm{CO}_{3}^{2-}, \mathrm{S}^{2-}$, acetato, $\mathrm{I}^{-}$ & Nenhum \\
\hline $\mathbf{P t}\left(\mathbf{P t}^{4+}\right)$ & $\mathrm{Na}^{+}, \mathrm{H}^{+}, \mathrm{Zn}^{2+}, \mathrm{Mn}^{2+}, \mathrm{K}^{+}, \mathrm{Fe}^{3+}$ & $\mathrm{F}^{-}$, Acetato, $\mathrm{I}^{-}, \mathrm{Cl}^{-}, \mathrm{SO}_{4}^{2-} \mathrm{NO}_{2}^{-}, \mathrm{S}^{2-}$ & $\begin{array}{l}\text { Éter etílico, ácido } \\
\text { rubeâmico, tioacetamida }\end{array}$ \\
\hline $\mathbf{R b}\left(\mathbf{R} \mathbf{b}^{+}\right)$ & $\begin{array}{l}\mathrm{Na}^{+}, \mathrm{Co}^{2+}, \mathrm{H}^{+}, \mathrm{UO}_{2}^{2+}, \mathrm{Zn}^{2+} \\
\quad \mathrm{Mn}^{2+}, \mathrm{K}^{+}, \mathrm{NH}_{4}^{+}, \mathrm{Fe}^{3+}\end{array}$ & $\begin{array}{c}\mathrm{PO}_{4}^{3-}, \mathrm{F}^{-}, \mathrm{NO}_{3}^{-}, \mathrm{ClO}_{4}^{-}, \text {Picrato, } \\
\text { Acetato, } \mathrm{I}^{-}, \mathrm{Cl}^{-}, \mathrm{SO}_{4}^{2-}, \mathrm{NO}_{2}^{-}\end{array}$ & Nenhum \\
\hline $\mathbf{R h}\left(\mathbf{R} \mathbf{h}^{3+}\right)$ & $\mathrm{Na}^{+}, \mathrm{H}^{+}, \mathrm{Zn}^{2+}, \mathrm{Mn}^{2+}, \mathrm{K}^{+}, \mathrm{Fe}^{3+}$ & $\mathrm{F}^{-}, \mathrm{I}^{-}, \mathrm{Cl}^{-}, \mathrm{S}^{2-}$ & Etanol, tioacetamida \\
\hline $\mathbf{S e}\left(\mathbf{S e}^{0}+\mathbf{S e}^{4+}\right)$ & $\mathrm{K}^{+}, \mathrm{H}^{+}, \mathrm{Zn}^{2+}, \mathrm{NH}_{4}^{+}, \mathrm{Fe}^{3+}, \mathrm{Sn}^{4+}$ & $\mathrm{Cl}^{-}, \mathrm{SO}_{4}^{2-}, \mathrm{I}^{-}, \mathrm{S}^{2-}, \mathrm{NO}_{3}^{-}$ & Nenhum \\
\hline $\mathrm{Te}\left(\mathrm{Te}^{4+}\right)$ & $\begin{array}{l}\mathrm{Na}^{+}, \mathrm{Zn}^{2+}, \mathrm{Mn}^{2+}, \mathrm{K}^{+}, \mathrm{NH}_{4}^{+}, \\
\quad \mathrm{Co}^{2+}, \mathrm{Fe}^{3+}, \mathrm{Sn}^{2+}, \mathrm{Ba}^{2+}\end{array}$ & $\begin{array}{c}\mathrm{NO}_{3}^{-}, \text {Acetato, } \mathrm{I}^{-}, \mathrm{Cl}^{-}, \mathrm{SO}_{3}^{2-}, \\
\mathrm{OH}^{-}, \mathrm{SCN}^{-}\end{array}$ & $\mathrm{CS}_{2}$, tiouréia \\
\hline $\mathbf{T l}\left(\mathbf{T l}^{+}\right)$ & $\mathrm{K}^{+}, \mathrm{Na}^{+}, \mathrm{NH}_{4}^{+}, \mathrm{Cr}^{3+}, \mathrm{Mn}^{2+}$ & $\mathrm{CO}_{3}^{2-}, \mathrm{Cl}^{-}, \mathrm{I}^{-}, \mathrm{NO}_{3}^{-}, \mathrm{OH}^{-}, \mathrm{CrO}_{4}^{2-}$ & Rodamina-B, tolueno \\
\hline
\end{tabular}

* referente apenas à sulfo-crômica em si: não foram considerados contaminantes oriundos do tratamento de vidrarias com este produto e os efluentes de $\mathrm{Ba}$, Sr e Tl que também contêm cromo, pois a quantidade de analitos adicionados é muito menor que aquela presente na sulfocrômica

As reações envolvendo o ouro são:

$2 \mathrm{AuCl}_{4}^{-}+3 \mathrm{Zn} \longrightarrow 2 \underline{\mathrm{Au}}+3 \mathrm{Zn}^{2+}+8 \mathrm{Cl}^{-}$

$2\left[\mathrm{Au}(\mathrm{OH})_{4}^{-}\right]+3 \mathrm{H}_{2} \mathrm{O}_{2} \longrightarrow 2 \underline{\mathrm{Au}}+3 \mathrm{O}_{2}+6 \mathrm{H}_{2} \mathrm{O}+2 \mathrm{OH}^{-}$

Apesar de ambos os métodos de redução serem eficientes, o método mais rápido e que gerou menos resíduo foi a redução do ouro com água oxigenada em meio básico. A reação foi facilmente controlável e não introduziu um íon metálico pesado no resíduo. Nos resíduos finais, nenhuma reação para ouro foi observada ${ }^{15-17}$. Como prata, paládio e mercúrio (interferentes) não estavam presentes, torna-se evidente que o objetivo de recuperar o ouro foi atingido.

\section{Tratamento dos resíduos de bário e de estrôncio}

Os resíduos contendo bário e estrôncio foram relativamente fáceis de serem tratados. Primeiramente ajustou-se o pH em 7 com solução de $\mathrm{NaOH}$; em seguida foi adicionado sulfato de sódio até cessar a precipitação. Os precipitados de sulfato de bário e de estrôncio foram secos ao ar; no caso do resíduo de bário, identificou-se um precipitado adicional, amarelo-claro, que era o cromato de bário. Estes sólidos são passíveis de incineração. A solução restante, que continha cromo hexavalente, foi incorporada ao tratamento dos resíduos deste elemento.

\section{Tratamento de resíduos contendo berílio}

Deve-se chamar a atenção quando se trata de manipular compostos de berílio: eles são altamente tóxicos. O resíduo contendo este elemento foi solubilizado em $\mathrm{HNO}_{3}\left(100{ }^{\circ} \mathrm{C}, 200 \mathrm{rpm}\right)$. Concentrou-se a solução até $40 \mathrm{~mL}$, obtendo-se uma solução esverdeada. Adicionou-se $\mathrm{NaOH}$ até $\mathrm{pH}$ 14. Tal procedimento foi realizado para precipitar $\mathrm{Fe}^{+3}$ e $\mathrm{Mn}^{+2}$ na forma de hidróxido, visto que neste $\mathrm{pH}$ o berílio forma hidroxi-complexo ${ }^{16}$. Assim o ajuste correto do $\mathrm{pH}$ é um parâmetro vital no isolamento do berílio, permitindo obtê-lo quantitativamente e livre de contaminação ${ }^{16}$. O precipitado castanho obtido foi filtrado, lavado com água fervente até cessar a presença de $\mathrm{Na}^{+}$; as águas de lavagem foram adicionadas ao decantado. Acidificouse a solução com $\mathrm{HCl}$ até $\mathrm{pH} 8,5$ (com precisão), digerindo-se o precipitado por $30 \mathrm{~min}\left(80{ }^{\circ} \mathrm{C}\right.$ e $\left.200 \mathrm{rpm}\right)$. Filtrou-se e lavou-se o precipitado branco $\left[\mathrm{Be}(\mathrm{OH})_{2}\right]$ com água $\left(100{ }^{\circ} \mathrm{C}\right)$ contendo $\mathrm{NH}_{4} \mathrm{OH}$ 
0,01 M. Os testes com Magneson $\mathrm{I}^{14-17}$ caracterizaram a ausência de berílio na solução final; esta foi neutralizada com $\mathrm{HCl}$, resultando numa solução incolor sem precipitado. As reações envolvendo o berílio são:

$\mathrm{Be}^{2+}+4 \mathrm{OH}^{-} \rightleftarrows\left[\mathrm{Be}(\mathrm{OH})_{4}^{2-}\right]$

$\left[\mathrm{Be}(\mathrm{OH})_{4}{ }^{2-}\right]+2 \mathrm{HCl} \longrightarrow \underline{\mathrm{Be}(\mathrm{OH})_{2}}+2 \mathrm{H}_{2} \mathrm{O}+2 \mathrm{Cl}^{-}$

Oito alunos utilizaram, cada um, $4 \mathrm{~mL}$ de uma solução contendo $10 \mathrm{mg} / \mathrm{mL} \mathrm{Be}^{2+}$ (total $320 \mathrm{mg}$ do elemento, correspondendo a 1530 mg do hidróxido). A massa obtida foi de $1370 \mathrm{mg}$ (rendimento $90 \%$ $\mathrm{p} / \mathrm{p})$.

\section{Tratamento dos resíduos de cobre e de cádmio}

Ao resíduo de cobre foi adicionada solução de $\mathrm{NaOH}$ até pH 7, obtendo-se um precipitado de hidróxido e uma solução azul intensa. Esse método não se mostrou totalmente eficaz, pois a precipitação de cobre com $\mathrm{NaOH}$ na presença de sais de amônio (Tabela 2) era apenas parcial devido à formação de aminocomplexos solúveis de cobre. Adicionou-se excesso de sulfeto de sódio para que o restante do cobre fosse precipitado como sulfeto. Filtrou-se o precipitado e no líquido que restou foi pesquisado cobre ${ }^{14-17}$; o resultado foi negativo. As reações que se verificam são:

$\mathrm{Cu}^{2+}+2 \mathrm{NaOH} \longrightarrow \mathrm{Cu}(\mathrm{OH})_{2}+2 \mathrm{Na}^{+}$
$\mathrm{Cu}^{2+}+4 \mathrm{NH}_{4} \mathrm{OH} \rightleftarrows\left[\mathrm{Cu}\left(\mathrm{NH}_{3}\right)_{4}\right]^{2+}+4 \mathrm{H}_{2} \mathrm{O}$
$\left[\mathrm{Cu}\left(\mathrm{NH}_{3}\right)_{4}\right]^{2+}+\mathrm{S}^{2-} \longrightarrow \underline{\mathrm{CuS}}+4 \mathrm{NH}_{3}$

A solução foi tratada com peróxido de hidrogênio (oxidar sulfeto a sulfato) e neutralizada. Ela se mostrou límpida e sem precipitado. Os metais listados no resíduo de cobre (Mn e Fe) já haviam co-precipitado com o elemento. Não se tentou isolar o cobre de seu precipitado, mas estudos nesse sentido estão em curso.

O procedimento experimental foi o mesmo para o cádmio, as reações envolvendo este elemento são análogas às do cobre. Ao contrário dos resíduos de cobre, que podem ser incinerados, não se pode fazer este procedimento para o cádmio (elemento altamente tóxico), pois pode haver liberação do mesmo no efluente gasoso do incinerador, com conseqüente contaminação ambiental.

\section{Tratamento de resíduos contendo cromo}

Sem sombra de dúvida este foi o resíduo mais difícil de trabalhar, pois além de existiren 10,5 litros de rejeito, seu tratamento mostrou-se muito delicado: grande parte deste resíduo correspondia a misturas sulfo-crômicas velhas, o que implicava na necessidade simultânea de eliminar a acidez ( $\mathrm{pH}$ inicial muito baixo) e de precipitar o cromo.

A uma amostra inicial de resíduo de $300 \mathrm{~mL}$ adicionou-se aos poucos $\mathrm{NaOH}$ sólido, sob vigorosa agitação, até pH 6 e solução de nitrato de bário. Percebeu-se que, mesmo com excesso deste sal, não se conseguia abater todo o cromo em solução, basicamente devido à presença de $\mathrm{Cr}^{3+}$, solúvel no meio. O precipitado, amarelo claro, realmente correspondia ao $\mathrm{BaCrO}_{4}$.

Resolveu-se trabalhar com carbonato de sódio e bissulfito de sódio sólidos. $\mathrm{O}$ carbonato de sódio servia para aumentar o $\mathrm{pH}$ da solução e o bissulfito para reduzir o cromato a cromo(III) e ainda consumir íons $\mathrm{H}^{+}$do meio. A escolha de reagentes sólidos não é fruto do acaso. $\mathrm{O}$ tratamento de 1 litro de sulfo-crômica velha por adição de volumes de base, redutor e mesmo de água poderia gerar até 20 litros de resíduo, o que configurava uma situação de difícil gerenciamento $^{18}$. O uso de sólidos evitava este aumento absurdo de volume. Foram adicionados (simultaneamente) cerca de $2 \mathrm{~kg}$ de carbonato de sódio e $1 \mathrm{~kg}$ de bissulfito de sódio para o tratamento de todo o resíduo de cromo, gastando-se $3 \mathrm{~h}$ pois a adição (sob agitação manual com bastão de vidro) devia ser lenta para minimizar efeitos de aquecimento e de espumação. Uma precaução tomada foi a realização do tratamento em banho de gelo. Obteve-se um precipitado verde escuro de hidróxido de cromo e uma solução castanha. À essa solução foram adicionados mais $700 \mathrm{~g}$ de bissulfito para que todo o cromo fosse obtido como um precipitado verde escuro. As reações são:

$$
\begin{aligned}
& 2 \mathrm{Cr}_{2} \mathrm{O}_{7}^{2-}+3 \mathrm{~S}_{2} \mathrm{O}_{5}^{2-}+10 \mathrm{H}^{+} \longrightarrow 4 \mathrm{Cr}^{3+}+6 \mathrm{SO}_{4}^{2-}+5 \mathrm{H}_{2} \mathrm{O} \\
& \mathrm{Cr}^{3+}+3 \mathrm{OH}^{-} \longrightarrow \stackrel{\mathrm{Cr}(\mathrm{OH})_{3}}{\longrightarrow} \mathrm{SO}_{2}^{2-}+2 \mathrm{Na}^{+}+\mathrm{H}_{2} \mathrm{O}
\end{aligned}
$$

$\mathrm{O}$ cheiro característico do $\mathrm{SO}_{2}$ foi percebido durante o tratamento do resíduo, de sorte que o procedimento experimental foi feito em capela, com exaustão. Um excesso de $\mathrm{Na}_{2} \mathrm{~S}_{2} \mathrm{O}_{5}$ se justifica para consumir os íons $\mathrm{H}^{+}$produzidos na precipitação do $\mathrm{Cr}(\mathrm{OH})_{3}$, bem como para compensar perdas pela liberação de $\mathrm{SO}_{2}$, o que foi mais notório à medida em que o agente oxidante $(\mathrm{Cr}(\mathrm{VI}))$ se exauria no meio. Ao precipitar o $\mathrm{Cr}$ (III) como hidróxido, o meio reacional tornou-se pastoso, sendo vertido em pote plástico e seco ao ar à temperatura ambiente. Em uma semana, o material tornou-se um sólido verde amarelado quebradiço. A recuperação do cromo não foi viabilizada dada a dificuldade de manuseio de seu resíduo final, e do controle de todos os analitos presentes.

\section{Tratamento dos resíduos de európio, neodímio, praseodímio e samário}

Tratou-se o resíduo de cada elemento com $\mathrm{HCl}$ a $60-70{ }^{\circ} \mathrm{C}$. Em seguida adicionou-se $\mathrm{HNO}_{3}$ concentrado para a completa solubilização de material insolúvel. Dessa forma eliminaram-se vários elementos presentes na solução sob a forma de $\mathrm{NH}_{3}, \mathrm{~N}_{2}, \mathrm{O}_{2}$, $\mathrm{CO}_{2}, \mathrm{CO}, \mathrm{I}_{2}$, além de se obter uma solução homogênea. A seguir, evaporou-se a solução até aproximadamente $20 \mathrm{~mL}$, dobrou-se esse volume com água destilada e evaporou-se novamente até quase secura (eliminação do excesso de $\mathrm{NO}_{2}$ ). Ao final da evaporação deixou-se esfriar e notou-se a presença de cristais brancos (tratava-se do $\mathrm{NaCl}$ ), a solução foi então filtrada e lavada com água destilada a $10{ }^{\circ} \mathrm{C}$ (até $\mathrm{pH}$ do filtrado neutro). Adicionou-se $\mathrm{HCl}$ até que a concentração final do ácido fosse igual a $2 \mathrm{M}$. Em seguida acrescentouse, vagarosamente, oxalato de amônio 0,3 M até cessar a precipitação $\left(60{ }^{\circ} \mathrm{C}, 200 \mathrm{rpm}\right)$. Centrifugou-se e lavou-se o precipitado com água $\left(60^{\circ} \mathrm{C}\right)$ contendo gotas de oxalato de amônio $0,01 \mathrm{M}$. A água de lavagem foi adicionada ao decantado e adicionou-se novamente oxalato de amônio, não fornecendo mais precipitado. A precipitação de oxalatos em meio $\mathrm{HCl} 2 \mathrm{M}$ é seletiva para toda a série lantanídia, ítrio e tório ${ }^{19-22}$.

Os precipitados obtidos, de coloração variando de verde (Pr), violeta $(\mathrm{Nd})$, amarelada $(\mathrm{Sm})$ a branco $(\mathrm{Eu})$ foram secos em cápsula de porcelana em mufla para eliminar a umidade $\left(150{ }^{\circ} \mathrm{C}\right.$ durante $1 \mathrm{~h}$ ). Em seguida calcinou-se na mesma mufla a $400{ }^{\circ} \mathrm{C}$ por $3 \mathrm{~h}$. Alternativamente, conseguiu-se fazer o procedimento global em chama de bico de Bunsen por $1 \mathrm{~h}$. Após resfriar em dessecador, pesouse a massa para determinação do fator gravimétrico (conversão oxalato-óxido). As reações de isolamento são:

$2 \mathrm{Ln}^{3+}+3 \mathrm{C}_{2} \mathrm{O}_{4}^{2-} \longrightarrow \underline{\mathrm{Ln}}_{2}\left(\underline{\mathrm{C}}_{2} \underline{\mathrm{O}}_{4}\right)_{3}$, onde $\mathrm{Ln}=\mathrm{Pr}, \mathrm{Nd}, \mathrm{Sm}, \mathrm{Eu}(12)$ $\underline{\mathrm{X}}_{2}\left(\underline{\mathrm{C}}_{2} \underline{\mathrm{O}}_{4}\right)_{3} \longrightarrow \underline{\mathrm{X}}_{2} \underline{\mathrm{O}}_{3}+3 \mathrm{CO}+3 \mathrm{CO}_{2}$, onde $\mathrm{X}=\mathrm{Nd}, \mathrm{Sm}$ ou Eu

$\mathrm{O}_{2}+\underline{\mathrm{Pr}}_{2}\left(\underline{\mathrm{C}}_{2} \underline{\mathrm{O}}_{4}\right)_{3} \longrightarrow \underline{\operatorname{Pr}}_{6} \underline{\mathrm{O}}_{11}+9 \mathrm{CO}+9 \mathrm{CO}_{2}$ 
$\mathrm{O}$ fator gravimétrico teórico, correspondendo à razão mássica $\mathrm{X}_{2} \mathrm{O}_{3}$ (ou $\left.\operatorname{Pr}_{6} \mathrm{O}_{11}\right) / \mathrm{X}_{2}\left(\mathrm{C}_{2} \mathrm{O}_{4}\right)_{3}$, varia de 0,61 a 0,63 , conforme o elemento. $\mathrm{O}$ fator experimental variou entre 0,60 e 0,65 . Os resíduos destes elementos foram gerados por dez alunos que trabalharam, cada um, com $4 \mathrm{~mL}$ de solução de cada elemento (10 mg/mL), o que dá um total de $400 \mathrm{mg}$ do lantanídio. Isto corresponde a cerca de 465 $\mathrm{mg}$ de óxido. As massas de óxido obtidas foram da ordem de $420 \mathrm{mg}$ (rendimento de cerca de $90 \% \mathrm{p} / \mathrm{p}$ ). O procedimento adotado, portanto, foi bastante satisfatório.

O resíduo foi neutralizado com $\mathrm{NaOH}$, obtendo-se um precipitado pardo contendo $\mathrm{Mn}, \mathrm{Fe}$ e $\mathrm{PO}_{4}^{3-}$, e uma solução incolor.

\section{Tratamento de resíduos contendo índio}

O resíduo de índio foi solubilizado em água-régia $\left(80{ }^{\circ} \mathrm{C}, 200\right.$ $\mathrm{rpm})$. A solução amarela foi filtrada, restando um precipitado amarelo (enxofre) que foi isolado. A solução foi concentrada sob ebulição moderada, ajustando-se o pH entre 3,5 e 4,5. A seguir, adicionou-se tioacetamida até cessar a formação de precipitado amarelo intenso $\left(\operatorname{In}_{2} \mathrm{~S}_{3}\right)$, a $90{ }^{\circ} \mathrm{C}$. A mistura foi filtrada e o sólido lavado com $\mathrm{HCl}$ e em seguida com água $\left(100{ }^{\circ} \mathrm{C}\right)$. No decantado mais os líquidos de lavagem caracterizou-se $e^{15-17}$ a presença de $\mathrm{Fe}^{3+}, \mathrm{Al}^{3+}$ e a ausência de $\mathrm{In}^{3+}$. O decantado foi neutralizado, formando-se um precipitado misto: castanho, contendo ferro e manganês, e um precipitado branco (hidróxido de alumínio).

Dez alunos empregaram, cada um, $4 \mathrm{~mL}$ de solução contendo $10 \mathrm{mg} \mathrm{In}{ }^{3+} / \mathrm{mL}$ (total $400 \mathrm{mg}$ In, equivalentes a $568 \mathrm{mg}$ do sulfeto). A massa de sulfeto obtida foi $520 \mathrm{mg}$ (rendimento $92 \% \mathrm{p} / \mathrm{p}$ ). A precipitação de índio na forma de sulfeto foi muito satisfatória, e o isolamento pode ser realizado diretamente, sem a eliminação dos interferentes da amostra, como ferro e manganês, pelo fato de que estes metais não precipitam na forma de sulfeto em meio ácido.

\section{Tratamento dos resíduos contendo irídio, ósmio, ródio e rutênio}

Ao volume do resíduo contendo o metal platínico (Tabela 2), adicionou-se água régia; a solução resultante foi concentrada, sob ebulição controlada, até aproximadamente $20 \mathrm{~mL}$. Dobrou-se esse volume com água e concentrou-se novamente a solução a $20 \mathrm{~mL}$. Esta operação foi repetida até a eliminação de $\mathrm{NO}_{2}$. A cor da solução tendia ao avermelhado, em função dos clorocomplexos presentes $\left(\mathrm{RuCl}_{6}^{3-}, \mathrm{RhCl}_{6}^{3-}, \mathrm{IrCl}_{6}{ }^{2-}\right.$ e $\left.\mathrm{OsCl}_{6}^{2-}\right)$. Devido à precipitação de uma grande quantidade de sal branco $(\mathrm{KCl})$, deixou-se esfriar e filtrou-se o excesso de $\mathrm{KCl}$, lavando com água $\left(10{ }^{\circ} \mathrm{C}\right)$ até filtrado incolor. $\mathrm{O}$ objetivo era evitar alguma dificuldade na redução do elemento devido à presença de clorocomplexos. No novo filtrado adicionou-se paulatinamente, zinco em pó $\left(60^{\circ} \mathrm{C}, 200 \mathrm{rpm}\right)$ até completa precipitação do metal, constatada pelo descoramento total da solução. O excesso de zinco foi destruído com adição de gotas de $\mathrm{HCl}$. Centrifugou-se a mistura, isolando o metal impuro do resíduo líquido. O metal platínico foi lavado com água a $60{ }^{\circ} \mathrm{C}$ e recentrifugado. Obteve-se ao final uma massa preta pulverulenta (negro de ósmio, ródio etc). As reações de isolamento dos metais são ${ }^{14-16}$ :

$\mathrm{Ir}^{4+}+2 \mathrm{Zn} \longrightarrow \underline{\mathrm{Ir}}+2 \mathrm{Zn}^{2+}\left(\mathrm{E}^{\mathrm{o}}=+1,65 \mathrm{~V}\right)$

$2 \mathrm{Os}^{3+}+3 \mathrm{Zn} \longrightarrow 2 \underline{\mathrm{Os}}+3 \mathrm{Zn}^{2+}\left(\mathrm{E}^{\mathrm{o}}=+1,55 \mathrm{~V}\right)$

$2 \mathrm{Ru}^{3+}+3 \mathrm{Zn} \longrightarrow 2 \underline{\mathrm{Ru}}+3 \mathrm{Zn}^{2+}\left(\mathrm{E}^{\mathrm{o}}=+1,43 \mathrm{~V}\right)$

$2 \mathrm{Rh}^{3+}+3 \mathrm{Zn} \longrightarrow 2 \underline{\mathrm{Rh}}+3 \mathrm{Zn}^{2+}\left(\mathrm{E}^{\mathrm{o}}=+1,20 \mathrm{~V}\right)$

A solução final foi neutralizada com $\mathrm{NaOH}$. O líquido é incolor e o precipitado contém Zn, Mn e Fe. Os testes com ácido rubeâmico e tiouréia deram resultado negativo, o que sugere um alto rendimento no isolamento dos metais de interesse ${ }^{14-16}$. A redução em meio ácido de metais nobres é uma excelente alternativa de isolamento a partir de soluções desprovidas de outras espécies não redutíveis ao estado elementar (Se, Te, etc).

\section{Tratamento dos resíduos de níquel e de manganês}

$\mathrm{O}$ resíduo de níquel foi tratado com $\mathrm{NaOH}$ até $\mathrm{pH} 7$ e, a seguir, com solução de carbonato de sódio em excesso. Filtrou-se e na solução restante testou-se o elemento com dimetil-glioxima ${ }^{14-17}$ (resultado negativo). Neutralizou-se a solução com $\mathrm{HCl}$ (sem a formação de precipitados). O mesmo foi feito para o resíduo de manganês. O uso de carbonato de sódio visava impedir alguma ressolubilização de outros metais presentes nos resíduos dos elementos em estudo (Zn) quando da precipitação do $\mathrm{Ni}$ ou do $\mathrm{Mn}$. As reações são:

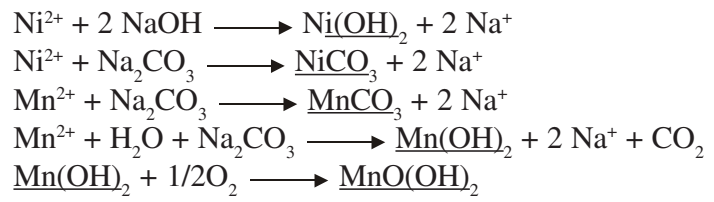

Os resíduos finais sólidos contendo $\mathrm{Mn}$ ou $\mathrm{Ni}$ foram levados à incineração.

\section{Tratamento de resíduos de chumbo}

$\mathrm{O}$ tratamento mostrou-se relativamente simples. $\mathrm{O} \mathrm{pH}$ foi ajustado em 7, adicionando-se $\mathrm{NaOH}$. Houve completa precipitação do chumbo. Filtrou-se o precipitado (contendo os hidróxidos de $\mathrm{Pb}, \mathrm{Cr}$ e $\mathrm{Zn}$ ).

Deve-se evitar um excesso, ainda que local, de $\mathrm{NaOH}$ para que parte do chumbo não se redissolva como complexo $\left[\mathrm{Pb}(\mathrm{OH})_{4}\right]^{2-}$. A alternativa segura para evitar perdas do elemento nesta etapa pela formação de hidroxicomplexos foi adicionar carbonato de sódio à solução de $\mathrm{NaOH}$, ainda mais que alguns metais presentes no resíduo original ( $\mathrm{Zn}, \mathrm{Cr}$ ) também se dissolvem em excesso de $\mathrm{NaOH}$. O sólido contendo chumbo foi enviado à incineração; e a solução final, incolor, não continha precipitados e metais pesados solúveis.

\section{Tratamento de resíduos contendo platina}

Inicialmente, verificou-se que não havia platina em solução ${ }^{14-17}$. Desse modo, a solução foi separada do sólido presente no resíduo. A cor amarela da solução é devida ao $\mathrm{Fe}^{3+}$ presente e não à $\mathrm{Pt}^{4+}$. Fez-se a abertura do sólido, marrom, com água-régia $\left(60^{\circ} \mathrm{C}\right)$. $\mathrm{O}$ sólido residual (enxofre elementar) ficou retido no papel de filtro e foi isolado.

A solução amarela, contendo $\mathrm{PtCl}_{6}^{2-}$, foi levada à quase secura, adicionando sempre um pouco de água destilada, até cessarem os vapores de $\mathrm{NO}_{2}$. O sólido amarelado formado foi dissolvido em cerca de $10 \mathrm{~mL}$ de água destilada, separando-se um sólido branco cristalino (mistura de $\mathrm{KCl}+\mathrm{NaCl}$ ). A solução foi alcalinizada com $\mathrm{NH}_{4} \mathrm{OH}$ concentrado até $\mathrm{pH} 10$. Houve a formação de um precipitado branco gelatinoso, contendo $\mathrm{Zn}, \mathrm{Mn}$ e $\mathrm{Sn}$, e que foi isolado da solução e lavado com $\mathrm{NH}_{4} \mathrm{OH}$ 0,01 M. Adicionou-se pouco a pouco sulfato de hidrazina $\left(80^{\circ} \mathrm{C}, 200 \mathrm{rpm}\right)$ até cessar a precipitação de um sólido preto (negro de platina). Após centrifugação, o sólido preto impuro foi lavado sucessivamente com $\mathrm{HCl} 2 \mathrm{M}, \mathrm{HNO}_{3} 3 \mathrm{M}$ e água destilada $\left(80^{\circ} \mathrm{C}\right)$.

A reação de obtenção da platina elementar é ${ }^{14-17}$ :

$\left[\mathrm{Pt}\left(\mathrm{NH}_{3}\right)_{6}\right]^{4+}+\mathrm{N}_{2} \mathrm{H}_{5}^{+}+5 \mathrm{OH}^{-} \longrightarrow \mathrm{N}_{2}+\underline{\mathrm{Pt}}^{\circ}+6 \mathrm{NH}_{3}+5 \mathrm{H}_{2} \mathrm{O}$

A solução residual, incolor, foi incorporada à solução amarela 
inicial e o conjunto foi neutralizado com $\mathrm{NaOH}$, formando-se um precipitado pardo volumoso e um filtrado incolor.

\section{Tratamento de resíduos contendo rubídio}

Apesar da enorme dificuldade em se isolar metais alcalinos por precipitação seletiva, dado que raros são os sais com solubilidade inferior a $0,01 \mathbf{M}^{14,16}$, tentou-se uma recuperação aplicável aos elementos mais pesados desta série $(\mathrm{K}, \mathrm{Rb}, \mathrm{Cs})$ via precipitação de seus percloratos. $\mathrm{O}$ volume de resíduo foi concentrado, sob ebulição moderada, até redução a $20 \%$ do volume inicial. Centrifugou-se a mistura, isolando um precipitado amarelo amorfo (testes positivos ${ }^{14-17}$ para $\mathrm{UO}_{2}^{2+}, \mathrm{Fe}^{3+}, \mathrm{Zn}^{2+}$ e $\mathrm{PO}_{4}^{3-}$ ). Este sólido foi lavado com água a $100{ }^{\circ} \mathrm{C}$ e as águas de lavagem foram adicionadas ao decantado da etapa de centrifugação. Concentrou-se esta solução até um volume final de $7 \mathrm{~mL}$ e adicionou-se $\mathrm{HClO}_{4}$ a 70\%, gota a gota, em gelo, seguido de repouso por $15 \mathrm{~min}$; centrifugou-se a mistura, obtendo-se um precipitado branco cristalino, que foi lavado com etanol, sendo a solução etanólica adicionada ao decantado amarelado obtido desta segunda centrifugação. Concentrou-se este decantado até volume final de $4 \mathrm{~mL}$, quando adicionouse, gota a gota, $\mathrm{HClO}_{4}$ em banho de gelo. Obteve-se um novo sólido branco cristalino, que foi centrifugado e lavado com etanol. A solução etanólica foi adicionada ao último decantado obtido. Após os testes de identificação realizados ${ }^{14-17}\left(\mathrm{Zn}^{+2}\right.$ - positivo; $\mathrm{PO}_{4}^{3-}$ - negativo e $\mathrm{UO}_{2}{ }^{2+}$ negativo), neutralizou-se a solução com $\mathrm{NaOH}$, formando-se um precipitado branco amarelado.

Os dois sólidos brancos cristalinos foram recristalizados em $\mathrm{H}_{2} \mathrm{O}$ $\left(100{ }^{\circ} \mathrm{C}\right)$ no mínimo volume possível e levados à mufla $\left(150{ }^{\circ} \mathrm{C}\right.$ por $1 \mathrm{~h})$ para eliminar a umidade e pesar a massa do suposto $\mathrm{RbClO}_{4}$ puro obtido. Em cápsula de porcelana, o sólido branco foi calcinado num forno $\left(450{ }^{\circ} \mathrm{C}\right)$ por aproximadamente $4 \mathrm{~h}$ para formar o $\mathrm{RbCl}$. A massa foi novamente pesada, após resfriamento em dessecador, para cálculo do fator gravimétrico. A decomposição do perclorato de rubídio ocorre segundo a reação:

$$
\mathrm{RbClO}_{4} \longrightarrow \mathrm{RbCl}+2 \mathrm{O}_{2}
$$

$\mathrm{O}$ fator gravimétrico teórico, correspondente à razão mássica $\mathrm{RbCl}_{\text {RbClO }}$ é 0,65 (120,92/184,92). A média experimental foi de 0,80. A explicação mais coerente para este resultado é admitir que se obteve uma mistura de cloreto e de perclorato de rubídio, e não perclorato puro, antes da calcinação do sólido branco.

O resíduo contendo rubídio foi gerado por oito alunos; cada um utilizou $4 \mathrm{~mL}$ de um solução contendo $10 \mathrm{mg} \mathrm{Rb} / \mathrm{mL}$, (massa total de $\mathrm{Rb}^{+}=320 \mathrm{mg}$ ou 452,8 mg de $\mathrm{RbCl}$ ). A massa total de $\mathrm{RbCl}$ recuperada foi de $340 \mathrm{mg}$ (rendimento $75 \% \mathrm{p} / \mathrm{p}$ ). A etapa crítica é a recristalização do perclorato.

O cloreto de rubídio purificado foi analisado por cromatografia de íons, o grau de pureza excedia a 99,5\% p/p.

\section{Tratamento de resíduos contendo selênio}

Ao volume do resíduo de selênio (Tabela 2) foi adicionado $\mathrm{HNO}_{3}$ concentrado; a solução resultante foi concentrada, sob ebulição controlada, até $50 \mathrm{~mL}$. Acrescentou-se mais $\mathrm{HNO}_{3}$ concentrado e concentrou-se novamente a solução a este volume. Adicionou-se água, evaporou-se e repetiu-se o processo até eliminação do $\mathrm{NO}_{2}$; ao final ajustou-se o volume a $100 \mathrm{~mL}$ com água. Adicionou-se, vagarosamente, $\mathrm{Na}_{2} \mathrm{~S}_{2} \mathrm{O}_{5}$ sólido, sob agitação magnética à temperatura ambiente até completa redução do selênio. O precipitado, que pode ser vermelho ( $\mathrm{Se}_{8}$, análogo ao $\mathrm{S}_{8}$ amarelo) ou vítreo (preto, outra forma alotrópica), foi centrifugado e lavado com água até $\mathrm{pH}$ neutro, sendo a seguir seco em estufa a $150{ }^{\circ} \mathrm{C}$ por $1 \mathrm{~h}$. Colocou-se no filtrado mais
$\mathrm{Na}_{2} \mathrm{~S}_{2} \mathrm{O}_{5}$, não havendo mais redução. Este método tem a vantagem de gerar um resíduo final sem a presença de metais pesados. A redução do selênio processa-se segundo a reação ${ }^{14-17}$ :

$$
\begin{aligned}
& 8 \mathrm{SeO}_{3}{ }^{2-}+8 \mathrm{Na}_{2} \mathrm{~S}_{2} \mathrm{O}_{5} \longrightarrow \underline{\mathrm{Se}}_{8}+8 \mathrm{Na}_{2} \mathrm{SO}_{4}+8 \mathrm{SO}_{4}{ }^{2-} \\
& \left(\mathrm{E}^{\mathrm{o}}=+1,24 \mathrm{~V}\right)
\end{aligned}
$$

Nove alunos utilizaram cada um, 0,12 g de selênio elementar em seus experimentos. A massa recuperada foi de $1,0 \mathrm{~g}$ (rendimento $93 \% \mathrm{p} / \mathrm{p}$ ), o que mostra a correção do procedimento efetuado. $\mathrm{O}$ excesso de $\mathrm{Na}_{2} \mathrm{~S}_{2} \mathrm{O}_{5}$ foi destruído com adição de $\mathrm{H}_{2} \mathrm{O}_{2}$ e aquecimento. O resíduo final foi neutralizado adicionando-se $\mathrm{NaOH}$. Os hidróxidos de $\mathrm{Fe}$, Mn e Sn precipitaram. O filtrado era incolor.

\section{Tratamento de resíduos contendo telúrio}

Solubilizou-se o resíduo em $\mathrm{HNO}_{3}$ concentrado, $\left(90-100{ }^{\circ} \mathrm{C}\right.$, $200 \mathrm{rpm}$ ). Filtrou-se o enxofre formado. Evaporou-se a solução à quase secura (eliminação $\mathrm{NO}_{2}$ ). Adicionou-se água, seguido de $\mathrm{HCl}$ $2 \mathrm{M}$, obtendo-se uma solução incolor. Realizou-se a redução do telúrio com adição lenta de sulfato de hidrazina sólido ou de zinco em pó, até cessar a precipitação $\left(60{ }^{\circ} \mathrm{C}\right.$ e $\left.200 \mathrm{rpm}\right)$. O procedimento de redução foi dificultado pela reoxidação parcial do telúrio, obrigando a adição de mais redutor. Após coagulação sob aquecimento $\left(80{ }^{\circ} \mathrm{C} /\right.$ $1 \mathrm{~h}$ ), o precipitado preto $\left(\mathrm{Te}^{\circ}\right)$ foi isolado por centrifugação, lavado com água para eliminar o excesso de sulfato de hidrazina, seco em estufa a $150{ }^{\circ} \mathrm{C}$ por $1 \mathrm{~h}$ e pesado. $\mathrm{O}$ resíduo final foi neutralizado, formando-se um precipitado pardo $\left(\mathrm{Fe}(\mathrm{OH})_{3}\right.$, podendo conter também zinco). $\mathrm{O}$ filtrado era incolor. No caso da presença de íons $\mathrm{N}_{2} \mathrm{H}_{5}{ }^{+}$, estes foram oxidados com peróxido de hidrogênio.

A obtenção de telúrio elementar sob adição de sulfato de hidrazina corresponde à reação:

$\mathrm{TeO}_{3}{ }^{2-}+\mathrm{N}_{2} \mathrm{H}_{5}^{+}+\mathrm{H}^{+} \longrightarrow \underline{\mathrm{Te}}+\mathrm{N}_{2}+3 \mathrm{H}_{2} \mathrm{O}$

A massa teórica de Te a ser obtida era de $0,96 \mathrm{~g}$ (oito alunos utilizaram, cada um, 0,12 g do elemento). A massa obtida foi de 1,02 $\mathrm{g}$, ou seja, um rendimento de $106 \%$. Embora dentro do erro experimental (10\%), existe a possibilidade de inclusão de contaminantes ( $\mathrm{Fe}, \mathrm{Co}$, $\mathrm{Zn}, \mathrm{Sn}, \mathrm{Ba}, \mathrm{Mn})$.

\section{Tratamento de resíduos contendo tálio}

Deve-se chamar a atenção quando se trata de manipular compostos de tálio: eles são altamente tóxicos. Ao resíduo de tálio foi adicionado $\mathrm{HNO}_{3}$ concentrado; o volume da solução resultante foi reduzido, sob ebulição controlada, até aproximadamente $40 \mathrm{~mL}$. Dobrouse esse volume com água e concentrou-se novamente a solução a este volume (eliminação de $\mathrm{NO}_{2}$ ). A próxima etapa foi a adição de solução de $\mathrm{NaOH}$ até ajustar o $\mathrm{pH}$ em aproximadamente 3. A oxidação do tálio foi feita com solução de $\mathrm{KMnO}_{4}$, sob agitação manual, no $\mathrm{pH}$ acima, até que todo o elemento fosse precipitado. Filtrou-se o precipitado marrom em papel de filtro, e lavou-se o mesmo com água destilada a $60{ }^{\circ} \mathrm{C}$ (até filtrado com $\mathrm{pH}$ neutro). Adicionou-se $\mathrm{HCl}$, obtendo-se uma solução de $\mathrm{TlCl}_{3}$, incolor. As reações que mostram o isolamento do tálio são $0^{14,16}$ :

$$
\begin{aligned}
& 2 \mathrm{H}^{+}+(\mathrm{x}-1) \mathrm{H}_{2} \mathrm{O}+10 \mathrm{Tl}^{+}+4 \mathrm{MnO}_{4}^{-} \longrightarrow 5 \underline{\mathrm{Tl}}_{2} \underline{\mathrm{O}}_{3} \cdot \mathrm{x} \underline{\mathrm{H}}_{2} \underline{\mathrm{O}}+4 \mathrm{Mn}^{2+} \\
& \left(\mathrm{E}^{\mathrm{o}}=+0,26 \mathrm{~V}\right) \\
& \underline{\mathrm{Tl}}_{2} \underline{\mathrm{O}}_{3} \cdot \mathrm{x} \underline{\mathrm{H}}_{2} \underline{\mathrm{O}}+6 \mathrm{HCl} \longrightarrow 2 \mathrm{TlCl}_{3}+(\mathrm{x}+3) \mathrm{H}_{2} \mathrm{O}
\end{aligned}
$$

Nas águas de lavagem detectou-se a presença de cromo e de manganês. Adicionou-se $\mathrm{NaOH}$ (até $\mathrm{pH} 10)$ e $\mathrm{H}_{2} \mathrm{O}_{2}(36 \%$ p/p), sob 
aquecimento $\left(60^{\circ} \mathrm{C}\right)$. Isolou-se o precipitado contendo $\mathrm{MnO}_{2}$. O filtrado foi conduzido ao tratamento feito para os resíduos contendo cromo. Os ensaios ${ }^{14-17}$ para tálio deram resultado negativo no filtrado. Para uma separação bem sucedida, deve-se ter em mente a manutenção do $\mathrm{pH}$ em torno de 3 , para que o tálio precipite seletivamente frente ao $\mathrm{Cr}$ e $\mathrm{Mn}$, e a criteriosa lavagem do precipitado para eliminação dos referidos interferentes. $\mathrm{O}$ resíduo de tálio foi gerado por oito alunos que utilizaram, cada um, $4 \mathrm{~mL}$ de solução contendo 30 $\mathrm{mg} \mathrm{Tl}+\mathrm{mL}$ (total $960 \mathrm{mg}$ ). Análises de absorção atômica do elemento utilizando a solução de $\mathrm{TlCl}_{3}$ indicam uma recuperação de $930 \mathrm{mg}$ (rendimento de $97 \%$ p/p), o que qualifica a rota proposta como excelente para isolamento do tálio.

\section{RESULTADOS E DISCUSSÃO}

\section{Caracterização visual e físico-química dos produtos finais}

A Tabela 3 ilustra os resultados obtidos após os tratamentos apresentados neste trabalho.

\section{Volume final dos resíduos}

O efeito de diluição é de grande importância na geração do resíduo final. Mesmo levando-se em conta que muitas evaporações foram feitas após a abertura do resíduo inicial, em geral, o volume final é maior do que o inicial. Os resíduos líquidos finais foram neutralizados, e esta neutralização é um importante fator que responde pelo seu volume. Naturalmente, a eliminação deste fator de diluição depende da natureza da solução a neutralizar. No caso de soluções ácidas, ao invés do uso de solução de $\mathrm{NaOH}$, poder-se-ia utilizar pastilhas desta base, ou ainda $\mathrm{Na}_{2} \mathrm{CO}_{3} / \mathrm{NaHCO}_{3}$ sólidos, exigindo apenas uma agitação efetiva para homogeneização e o controle do efeito de espumação. Para soluções alcalinas, apela-se para ácidos de maior concentração apesar da manipulação ser mais delicada.

Outro ponto capital é a etapa de lavagem dos precipitados contendo o elemento de interesse. Tal processo é inevitável em se tratando de isolamento de uma fase sólida a partir de uma solução, a fim de remover componentes adsorvidos e assim garantir um grau de pureza adequado do produto final. Dependendo da natureza do precipitado, diversas lavagens (ou mesmo várias reprecipitações) são essenciais para se chegar a esse fim. Assim, percebe-se que a recuperação de elementos via precipitação seletiva implica necessariamente na geração de um efluente líquido final devido às etapas de lavagem. A própria etapa de lavagem é um capítulo à parte. A escolha do líquido de lavagem deve ser tal para minimizar pepitização de precipitados. Em geral, centrifugou-se e não se filtrou o sólido contendo o elemento recuperado. $\mathrm{O}$ uso de papéis de filtro levaria a sérias perdas de precipitados untuosos e finamente divididos (metais nobres, selênio, telúrio, ouro, prata, etc); a lavagem era efetuada por ressuspensão do sólido no líquido de lavagem.

O procedimento de abertura do resíduo e a adição do agente de isolamento do elemento possuem importância secundária. Em geral, após a abertura, é necessário eliminar o excesso do agente de abertura para não interferir nas etapas subseqüentes; isto é feito normalmente por evaporação da solução de abertura. Adicionalmente, a abertura simplifica a composição do resíduo a ser tratado (eliminação de $\mathrm{S}^{2-}, \mathrm{I}^{-}, \mathrm{H}^{+}$ou $\mathrm{OH}^{-}, \mathrm{NH}_{3}$, etc). Muitos dos agentes de isolamento são redutores sólidos $\left(\mathrm{Zn}^{\circ},\left(\mathrm{N}_{2} \mathrm{H}_{5}\right)_{2} \mathrm{SO}_{4}\right)$ ou soluções concentradas $\left(\mathrm{HClO}_{4}, \mathrm{NH}_{4} \mathrm{OH}\right)$ de pequeno efeito de volume.

\section{Componentes do resíduo final}

Embora vários elementos presentes nos resíduos possam ser eli- minados durante o processamento $\left(\mathrm{I}_{2}, \mathrm{NH}_{3}, \mathrm{O}_{2}\right)$ por reações ácidobase ou redox, existe a inevitável adição de espécies decorrentes das etapas de abertura e de isolamento do elemento. No primeiro caso, corresponde basicamente aos ânions dos ácidos de origem $\left(\mathrm{NO}_{3}^{-}, \mathrm{Cl}^{-}\right)$; no segundo, o espectro de analitos é bem mais variado: metais ( $\mathrm{Sn}$, $\mathrm{Zn}$, etc) ou espécies não-metálicas $\left(\mathrm{OH}^{-}, \mathrm{N}_{2} \mathrm{H}_{5}^{+}, \mathrm{S}^{2-}\right)$.

É aqui que se concentra toda a atenção, pois estes analitos representam problemas ambientais em potencial. Para minimizar tais problemas, algumas posturas determinadas pelo bom senso e pela resolução $\mathrm{N}^{\circ} 20$ do Conselho Nacional do Meio Ambiente (CONAMA) ${ }^{18}$, devem ser seguidas: com a neutralização, os metais pesados normalmente precipitarão como hidróxidos ou como sais de algum ânion apropriado $\left(\mathrm{PO}_{4}^{3-}, \mathrm{F}^{-}, \mathrm{C}_{2} \mathrm{O}_{4}{ }^{2-}\right.$, etc). Isto implica em separação deste precipitado seguido de uma análise do efluente para fins de descarte. Caso os potenciais redox permitam, a substituição de um redutor metálico por um sal como sulfato de hidrazina ou a utilização de uma solução facilmente eliminável, como $\mathrm{H}_{2} \mathrm{O}_{2}$ e $\mathrm{HCOOH}$ evita o inconveniente de introduzir metais pesados no resíduo final.

\section{Aspectos gerais}

Apesar do sucesso no processamento de diversos rejeitos, notou-se que o grau de dificuldade variou enormemente, caso a caso. Verificou-se que para resíduos de composição simples os procedimentos aplicados baseados nas regras de solubilidade e em reações redox deram resultados satisfatórios, mas para amostras industriais ou desconhecidas a complexidade será imprevisível, porque a qualidade do resíduo varia conforme sua origem. Assim, não há como propor uma rota única para a recuperação de cada elemento ou de preparo para disposição final, mas adaptações a partir das propostas feitas. O requisito decisivamente favorável para que possam ser feitas adaptações dessas propostas é a coleta seletiva e o conhecimento, mesmo que apenas a nível qualitativo, da composição dos resíduos, com base nos roteiros de aula das disciplinas em questão, de procedimentos analíticos em laboratórios de pesquisa ou das rotas de processamento industrial. Exemplos do valor da coleta seletiva vêm a seguir: se fosse misturado mercúrio (não incinerável) a um resíduo de chumbo (incinerável), teríamos a geração de um volume de resíduo não incinerável muito maior. Foi o que aconteceu com certos resíduos do passivo (sem rótulo) que foram analisados no IQ/UFRJ; se os resíduos da série lantanídia ou os metais platínicos fossem agrupados, o método de isolamento proposto neste trabalho serviria para isolar o conjunto de elementos destas séries, mas não para separá-los entre si, o que exigiria um tedioso trabalho adicional (desnecessário com a coleta seletiva).

É importante evitar que os resíduos fiquem longo tempo estocados, por duas razões: (a) evitar reações insidiosas que possam levar, com o tempo, à geração de gases dentro dos recipientes, à formação de compostos explosivos, à formação de borras difíceis de manipular e à geração de calor no meio reacional; (b) evitar que o rótulo de identificação desbote ou desapareça com o tempo. O resíduo desconhecido é um dos maiores desafios do laboratorista e seu processamento pode ser longo, penoso e caro. Sem o conhecimento, ao menos qualitativo, do que se coloca num frasco de resíduo, a situação se complica consideravelmente.

A coleta de resíduos é uma estratégia que necessariamente exige conscientização coletiva: sem a participação de todos, não se obterá o sucesso quanto à minimização ou eliminação da geração de resíduos. Os volumes e a diversidade dos resíduos gerados realmente classificam as universidades como poluidoras em potencial. Há cogitações de que elas podem ser enquadradas como unidades poluidoras pelas agências ambientais brasileiras, o que exigirá que se ajustem às legislações pertinentes. 
Tabela 3 - Caracterização dos produtos finais após os tratamentos

\begin{tabular}{|c|c|c|c|c|}
\hline Elemento & $\begin{array}{l}\text { Aspecto visual do resíduo } \\
\text { final (sólido e líquido) }\end{array}$ & $\begin{array}{l}\text { Volume inicial do } \\
\text { resíduo }(\mathrm{mL})\end{array}$ & $\begin{array}{l}\text { Volume final do } \\
\text { resíduo líquido }(\mathrm{mL})\end{array}$ & $\begin{array}{l}\text { Aspecto do produto contendo } \\
\text { o elemento de interesse }\end{array}$ \\
\hline $\operatorname{Ag}\left(\mathbf{A g}^{0}\right)$ & $\begin{array}{l}\text { Sólido branco } \\
\text { Solução incolor }\end{array}$ & 3300 & 3600 & $\begin{array}{l}\text { Sólido preto } \\
{\text { (prata metálica })^{\mathrm{a}}}\end{array}$ \\
\hline $\mathbf{A u}\left(\mathbf{A u}^{3+}\right)$ & $\begin{array}{l}\text { Sólido pardo } \\
\text { Solução incolor }\end{array}$ & 140 & 180 & $\begin{array}{l}\text { Sólido amarelo } \\
\left(\mathrm{AuCl}_{3}\right)^{\mathrm{a}}\end{array}$ \\
\hline $\mathbf{B a}\left(\mathbf{B a}^{2+}\right)$ & $\begin{array}{l}\text { Sólidos amarelo e branco } \\
\text { Solução alaranjada }\end{array}$ & 3000 & $3200^{*}$ & $\begin{array}{l}\text { Sólidos amarelo e branco } \\
\left(\mathrm{BaCrO}_{4}+\mathrm{BaSO}_{4}\right)^{\mathrm{b}}\end{array}$ \\
\hline $\mathbf{B e}\left(\mathbf{B e}^{2+}\right)$ & $\begin{array}{l}\text { Sólido marrom } \\
\text { Solução incolor }\end{array}$ & 200 & 100 & $\begin{array}{l}\text { Sólido branco } \\
{\left[\mathrm{Be}(\mathrm{OH})_{2}\right]^{\mathrm{a}}}\end{array}$ \\
\hline $\mathrm{Cd}\left(\mathrm{Cd}^{2+}\right)$ & $\begin{array}{l}\text { Sólido amarelo-alaranjado } \\
\text { Solução incolor }\end{array}$ & 1500 & 2000 & $\begin{array}{l}\text { Sólido amarelo-alaranjado } \\
\left(\mathrm{Cd}(\mathrm{OH})_{2}+\mathrm{CdS}\right)^{\mathrm{c}}\end{array}$ \\
\hline $\mathrm{Cr}\left(\mathrm{Cr}^{3+}\right)$ & $\begin{array}{l}\text { Sólido verde-amarelado, } \\
\text { sem líquido }\end{array}$ & $10500^{* *}$ & Não houve & $\begin{array}{l}\text { Sólido verde-amarelado } \\
{\left[\mathrm{Cr}(\mathrm{OH})_{3}\right]^{\mathrm{b}}}\end{array}$ \\
\hline $\mathrm{Cu}\left(\mathrm{Cu}^{2+}\right)$ & $\begin{array}{l}\text { Sólidos azul e marrom } \\
\text { Solução incolor }\end{array}$ & 2500 & 2850 & $\begin{array}{l}\text { Sólidos azul e marrom } \\
\left(\mathrm{Cu}(\mathrm{OH})_{2}+\mathrm{CuS}\right)^{\mathrm{b}}\end{array}$ \\
\hline $\mathbf{E u}\left(\mathbf{E u}^{3+}\right)$ & $\begin{array}{l}\text { Sólido pardo } \\
\text { Solução incolor }\end{array}$ & 33 & 130 & $\begin{array}{l}\text { Sólido branco } \\
\left(\mathrm{Eu}_{2} \mathrm{O}_{3}\right)^{\mathrm{a}}\end{array}$ \\
\hline $\operatorname{In}\left(\operatorname{In}^{3+}\right)$ & $\begin{array}{l}\text { Sólidos castanho e branco } \\
\text { Solução incolor }\end{array}$ & 70 & 100 & $\begin{array}{l}\text { Sólido amarelo } \\
\left(\mathrm{In}_{2} \mathrm{~S}_{3}\right)^{\mathrm{a}}\end{array}$ \\
\hline $\mathbf{I r}\left(\mathbf{I r}^{0}\right)$ & $\begin{array}{l}\text { Sólidos branco e pardo } \\
\text { Solução incolor }\end{array}$ & 30 & 60 & $\begin{array}{l}\text { Sólido preto } \\
\text { (irídio metálico) }^{\mathrm{a}}\end{array}$ \\
\hline $\mathrm{Mn}\left(\mathrm{Mn}^{2+}+\mathrm{Mn}^{4+}\right)$ & $\begin{array}{l}\text { Sólido marrom } \\
\text { Solução incolor }\end{array}$ & 1500 & 1700 & $\begin{array}{l}\text { Sólido marrom } \\
\left(\mathrm{MnCO}_{3}+\mathrm{MnO}(\mathrm{OH})_{2}\right)^{\mathrm{b}}\end{array}$ \\
\hline $\mathbf{N d}\left(\mathbf{N d}^{3+}\right)$ & $\begin{array}{l}\text { Sólido pardo } \\
\text { Solução incolor }\end{array}$ & 33 & 130 & $\begin{array}{l}\text { Sólido violeta } \\
\left(\mathrm{Nd}_{2} \mathrm{O}_{3}\right)^{\mathrm{a}}\end{array}$ \\
\hline $\mathbf{N i}\left(\mathbf{N i}^{2+}\right)$ & $\begin{array}{l}\text { Sólido verde } \\
\text { Solução incolor }\end{array}$ & 2500 & 2750 & $\begin{array}{l}\text { Sólido verde } \\
\left(\mathrm{Ni}(\mathrm{OH})_{2}+\mathrm{NiCO}_{3}\right)^{\mathrm{b}}\end{array}$ \\
\hline Os $\left(\mathrm{Os}^{0}\right)$ & $\begin{array}{l}\text { Sólidos pardo e branco } \\
\text { Solução incolor }\end{array}$ & 50 & 70 & $\begin{array}{l}\text { Sólido preto } \\
\text { (ósmio metálico) }^{\mathrm{a}}\end{array}$ \\
\hline $\mathbf{P b}\left(\mathbf{P b}^{2+}\right)$ & $\begin{array}{l}\text { Sólido esbranquiçado } \\
\text { Solução incolor }\end{array}$ & 2800 & 3200 & $\begin{array}{l}\text { Sólido esbranquiçado } \\
{\left[\mathrm{Pb}(\mathrm{OH})_{2}\right]^{\mathrm{b}}}\end{array}$ \\
\hline $\operatorname{Pr}\left(\operatorname{Pr}^{3+}+\operatorname{Pr}^{4+}\right)$ & $\begin{array}{l}\text { Sólidos branco e pardo claro } \\
\text { Solução incolor }\end{array}$ & 100 & 120 & $\begin{array}{l}\text { Sólido preto } \\
\left(\mathrm{Pr}_{6} \mathrm{O}_{11}\right)^{\mathrm{a}}\end{array}$ \\
\hline $\mathbf{P t}\left(\mathbf{P t}^{0}\right)$ & $\begin{array}{l}\text { Sólido pardo } \\
\text { Solução incolor }\end{array}$ & 15 & 120 & $\begin{array}{l}\text { Sólido marrom } \\
\text { (platina metálica) }^{\mathrm{a}}\end{array}$ \\
\hline $\mathbf{R b}\left(\mathbf{R} \mathbf{b}^{+}\right)$ & $\begin{array}{l}\text { Sólido branco-amarelado } \\
\text { Solução amarelada }\end{array}$ & 40 & 25 & $\begin{array}{l}\text { Sólido branco } \\
(\mathrm{RbCl})^{\mathrm{a}}\end{array}$ \\
\hline $\mathbf{R h}\left(\mathbf{R h}^{0}\right)$ & $\begin{array}{l}\text { Sólidos pardo e branco } \\
\text { Solução incolor }\end{array}$ & 80 & 80 & $\begin{array}{l}\text { Sólido preto } \\
\text { (ródio metálico) }^{\mathrm{a}}\end{array}$ \\
\hline $\mathbf{R u}\left(\mathbf{R u}^{0}\right)$ & $\begin{array}{l}\text { Sólido marrom } \\
\text { Solução incolor }\end{array}$ & 25 & 60 & $\begin{array}{l}\text { Sólido preto } \\
\text { (rutênio metálico) }^{\mathrm{a}}\end{array}$ \\
\hline $\operatorname{Se}\left(\mathrm{Se}^{0}\right)$ & $\begin{array}{l}\text { Sólido pardo } \\
\text { Solução incolor }\end{array}$ & 300 & 140 & 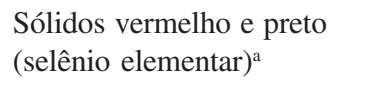 \\
\hline $\mathrm{Sm}\left(\mathrm{Sm}^{3+}\right)$ & $\begin{array}{l}\text { Sólido pardo } \\
\text { Solução incolor }\end{array}$ & 40 & 160 & $\begin{array}{l}\text { Sólido amarelado } \\
\left(\mathrm{Sm}_{2} \mathrm{O}_{3}\right)^{\mathrm{a}}\end{array}$ \\
\hline $\mathrm{Sr}\left(\mathrm{Sr}^{2+}\right)$ & $\begin{array}{l}\text { Sólido branco } \\
\text { Solução alaranjada }\end{array}$ & 3000 & $3150^{*}$ & $\begin{array}{l}\text { Sólido branco } \\
\left(\mathrm{SrSO}_{4}\right)^{\mathrm{b}}\end{array}$ \\
\hline $\operatorname{Te}\left(\mathrm{Te}^{0}\right)$ & $\begin{array}{l}\text { Sólido pardo } \\
\text { Solução incolor }\end{array}$ & 170 & 100 & $\begin{array}{l}\text { Sólido preto } \\
\text { (telúrio elementar) }^{\mathrm{a}}\end{array}$ \\
\hline $\mathrm{Tl}\left(\mathrm{Tl}^{3+}\right)$ & $\begin{array}{l}\text { Sólido marrom } \\
\text { Solução amarelo-alaranjada }\end{array}$ & 100 & $130^{*}$ & $\begin{array}{l}\text { Solução incolor } \\
\left(\mathrm{TlCl}_{3}\right)^{\mathrm{a}}\end{array}$ \\
\hline
\end{tabular}

* tratados juntamente com os resíduos de cromo; ** resíduos de Cr mais efluentes dos resíduos de Ba, Sr e Tl; ${ }^{~}$ material a ser reaproveitado nos laboratórios; ${ }^{\mathrm{b}}$ material a ser enviado para incineração; ${ }^{\mathrm{c}}$ material a ser enviado para aterro classe I. 
O tratamento de resíduos contendo metais exige conhecimentos práticos da chamada "química clássica"14-17, basicamente reações de precipitação; isto vai de encontro com o que se faz em outras universidades e nas indústrias que têm programas de gerenciamento de resíduos $^{1-7}$. Quanto ao destino final dos resíduos sólidos, eles geralmente podem ser levados à incineração, exceto os que contêm $\mathrm{Hg}$, $\mathrm{Cd}, \mathrm{Se}, \mathrm{F}, \mathrm{Br}$, I e Tl. Para estes, a rota é encapsulá-los em cimento, concreto, etc. para colocação direta em aterros classe I (resíduos perigosos), segundo as normas da ABNT (10.004) ${ }^{2-6}$. Espécies como $\mathrm{S}^{2-}, \mathrm{CN}^{-}, \mathrm{N}_{2} \mathrm{H}_{5}^{+}$etc. merecem atenção. Por exemplo, tioacetamida não hidrolisada é cancerígena ao homem, bem como o íon $\mathrm{N}_{2} \mathrm{H}_{5}{ }^{+} \mathrm{e}$ derivados $\left(\mathrm{N}_{2} \mathrm{H}_{4}, \mathrm{NH}_{2} \mathrm{OH}\right.$, etc). $\mathrm{O}$ íon $\mathrm{S}^{2-}$ é tóxico por ser facilmente convertido em $\mathrm{H}_{2} \mathrm{~S}$, mais tóxico que cianeto. As providências a serem tomadas implicam na destruição dessas espécies por oxidantes apropriados, $\left(\mathrm{OCl}^{-}, \mathrm{H}_{2} \mathrm{O}_{2} \ldots\right)$ antes da neutralização final. $\mathrm{O}$ simples aquecimento também pode eliminar aditivos como $\mathrm{H}_{2} \mathrm{O}_{2}$, ácido fórmico e oxalatos. Se os efluentes líquidos forem descartados num corpo d'água, é necessária uma análise prévia de teores dos analitos presentes nos mesmos (sulfatos, cloretos, nitratos etc) para que eles se ajustem às normas preconizadas na resolução $\mathrm{N}^{\mathrm{o}} 20 \mathrm{do}$ CONAMA $^{18}$.

\section{CONCLUSÃO}

O trabalho levou a uma experiência muito grande em química em solução aquosa e em tratamento de rejeitos para os alunos participantes. Além disso, surgiu espontaneamente uma preocupação muito grande acerca de todo tipo de substância que é descartada indiscriminadamente na pia dos laboratórios, não só de disciplinas experimentais como também em laboratórios de pesquisa.

Os resultados obtidos permitem distinguir dois tipos de produto final contendo o elemento-chave no resíduo inicial: (a) aqueles contendo metais preciosos (metais do grupo da platina, ouro, prata), selênio, telúrio, elementos tóxicos (berílio, tálio), elementos da série lantanídia, índio e rubídio. Neste caso, tais elementos foram isolados com bom rendimento e podem ser reutilizados nos laboratórios; (b) materiais que podem ser levados à incineração (cromo, manganês, chumbo, níquel, cobre, estrôncio e bário) ou que, encapsulados, podem ser dispostos em aterros classe I (cádmio). Incluem-se também neste caso os resíduos sólidos finais após o isolamento dos elementos listados em (a). Todas as rotas de preparação para descarte final de sólidos inservíveis foram bem sucedidas. Por outro lado, a incineração ou o encapsulamento não são necessariamente as únicas alternativas; por exemplo, estudos estão sendo feitos com os resíduos de cobre, níquel e bário para que tais elementos sejam isolados a partir dos resíduos obtidos neste trabalho. Preocupou-se em checar que os efluentes líquidos finais eram apenas soluções neutras de sais não-tóxicos. Em particular, apesar do volume global dos efluentes líquidos finais (cerca de 29,3 litros) ser inferior ao dos resíduos originais (cerca de 32 litros), os processos de tratamento mostrados neste trabalho geralmente levaram a um aumento de volume do efluente final. A discrepância acima foi devida ao fato do resíduo de cromo (volume inicial 10,5 litros) não ter gerado efluente líquido final.
Considerando grandes quantidades de resíduos, ou a existência de elementos que não podem ser levados à incineração, é necessário realizar um estudo mais aprimorado da disposição destes resíduos em aterros classe I (perigosos) ou a utilização deles como matériaprima em outros processos químicos, tal como estabelecido nas chamadas "bolsas de resíduos" implantadas no país.

\section{AGRADECIMENTOS}

À Fundação José Bonifácio (FUJB) pelo auxílio financeiro. Ao Laboratório de Desenvolvimento Analítico (LADA) do Departamento de Química Analítica do IQ/UFRJ pelas análises por absorção atômica e cromatografia de íons.

\section{REFERÊNCIAS}

1. Cunha, C. J.; Quim. Nova 2001, 24, 424.

2. Amaral, S. T.; Machad, P. F. L.; Peralba, M. C. R.; Camara, M. R.; Santos, T.; Berleze, L.; Falcão, H. L.; Martinelli, M.; Gonçalves, R. S.; Oliveira, E. R.; Brasil, J. L.; Araújo, M. A.; Borges, A. C.; Quim. Nova 2001, 24, 419.

3. Baader, W. J.; Faria, D. L. A.; Marzorati, L.; Di Vitta, C.; Serrano, S. H. P.; Bertotti, M.; Baptista, M.; Resumos da $24^{a}$ Reunião Anual da Sociedade Brasileira de Química, Poços de Caldas, Brasil, 2001.

4. Reche, T. V.; Cortez, F. A.; Alberguine, L. B.; Resumos da $23^{a}$ Reunião Anual da Sociedade Brasileira de Química, Poços de Caldas, Brasil, 2000.

5. Jardim, W. F.; Quim. Nova 1998, 21, 671.

6. Micaroni, R. C. C. M.; Bueno, M. I. M. S.; Jardim, W. F.; Resumos da $23^{a}$ Reunião Anual da Sociedade Brasileira de Química, Poços de Caldas, Brasil, 2000.

7. Pereira, P. S.; Martinez, M. S.; Januário, A. H.; Queiroz, M. E. C.; Kronka, E. A. M.; Paschoalato, C. F. P. R.; Lopes, C. S. G.; Oliveira, R. A.; Resumos da $24^{a}$ Reunião Anual da Sociedade Brasileira de Química, Poços de Caldas, Brasil, 2001

8. Armour, M. A.; J. Chem. Educ. 1998, 65, 64.

9. Nacional Research Council, Chemical Science and Technology; Prudent Practices in the Laboratory: Handling and Disposal of Chemicals, Washington, 1995.

10. Micaroni, R. C. C. M.; Bueno, M. I. M. S.; Resumos da $24^{a}$ Reunião Anual da Sociedade Brasileira de Química, Poços de Caldas, Brasil, 2001.

11. http://lqa.iqm.unicamp.br, acessada em Abril 2002.

12. http://www.udel.edu/OHS/chemicalwasteminimize.html, acessada em Dezembro 2001.

13. Freindinger, N.; Projeto de curso, Departamento de Química Analítica/IQ/ UFRJ, 1998 .

14. Lurie, J.; Handbook of Analytical Chemistry, Mir Publishers: Moscou, 1978, caps. 3, 6 e 10.

15. Vogel, A. I.; Química Analítica Qualitativa, 5 ed., Editora Mestre Jou: São Paulo, 1981, cap. III.

16. Charlot, G.; Chimie Analytique Quantitative, 2a ed., Masson et Cie: Paris, 1974, p. 171-305.

17. Vaitsman, S. D.; Bittencourt, O. A.; Ensaios Químicos Qualitativos, Editora Interciência: Rio de Janeiro, 1995, caps. 2 e 4.

18. Resolução do Conselho Nacional do Meio Ambiente (CONAMA) no 20, de 18/06/1986, publicada no Diário Oficial da União em 30/07/1986.

19. Abrão, A.; Química e Tecnologia das Terras Raras, CETEM/CNPq: Rio de Janeiro, 1994

20. Akhmetov, N.; Inorganic Chemistry, Mir Publishers: Moscou, 1973, cap. 4.

21. Amorim, H.; Tema, CETEM/CNPq, Rio de Janeiro, 1995, ano II, nº 1, p. $1-4$.

22. Couto, P. O. R.; Tema, CETEM/CNPq, Rio de Janeiro, 1995, ano II, nº 2 , p. 1-6. 